\title{
Effect of cadmium on collagen content and solubility in rat bone
}

\author{
Anna Galicka ${ }^{1 凶}$, Małgorzata M. Brzóska ${ }^{2}$, Krystyna Średzińska ${ }^{1}$ and \\ Andrzej Gindzienski ${ }^{1}$ \\ ${ }^{1}$ Department of Medical Chemistry, ${ }^{2}$ Department of Toxicology, Medical University of \\ Bialystok, Biatystok, Poland
}

Received: 05 February, 2004; revised: 23 April, 2004; accepted: 17 May, 2004

Key words: cadmium, collagen, bone, rat

\begin{abstract}
The toxic action of cadmium in the bone tissue is known, but its mechanisms are still unexplained. We examined whether Cd influences collagen content and its solubility in the femoral bone of three-week-old female rats exposed to 5 or $50 \mathrm{mg} \mathrm{Cd} / \mathrm{lin}$ drinking water. Non-cross linked collagen was extracted with $0.5 \mathrm{M}$ acetic acid, and two acid-insoluble collagen fractions were extracted with pepsin and $4.0 \mathrm{M}$ guanidine hydrochloride, respectively. SDS/PAGE showed the presence of two collagen types, I and V, in all three extracted fractions. Exposure of rats to Cd for 6 months increased the amount of acid-soluble collagens type $I$ and $V$ and decreased the level of acid-insoluble collagens. The amount of total collagen extracted from the bones of rats exposed to $50 \mathrm{mg} \mathrm{Cd} / \mathrm{l}$ was reduced by about $14 \%$ as compared to control and those intoxicated with $5 \mathrm{mg} \mathrm{Cd} / \mathrm{l}$. The solubility of type I bone collagen (determined as the percentage of acetic-soluble fraction of total collagen) was increased 2.9- and 3.0-fold in rats intoxicated with 5 and $50 \mathrm{mg} \mathrm{Cd} / 1$, respectively. Similarly, the solubility of type $\mathrm{V}$ collagen was increased 2.3- and 2.7-fold, respectively. Our results indicate that $\mathrm{Cd}$ treatment affects bone collagen by decreasing its content and increasing its solubility.
\end{abstract}

Cadmium (Cd) is one of the most toxic heavy metals, a common contaminant of the natural and occupational environment creating a serious health risk (Järup, 2002). Long-term exposure to this metal leads mainly to the dam- age of kidney and bones. Skeletal injury such as osteopenia, osteoporosis and/or osteomalacia with increased incidence of fractures and pathological fractures were noted as a result of human and animal exposure to $\mathrm{Cd}$

\footnotetext{
${ }^{\circledR}$ Corresponding author: Anna Galicka, Department of Medical Chemistry, Medical University of Bialystok, 15-230 Białystok 8, Poland; tel.: (48 85) 748 5673; fax: (48 85) 748 5416; e-mail: angajko@amb.ac.bialystok.pl
} 
(Katsuta et al., 1994; Brzóska et al., 2001). However, the mechanisms of the damaging action of $\mathrm{Cd}$ in the bone have not been fully clarified yet (Kjellström, 1992). It was reported that $\mathrm{Cd}$ intoxication has direct and indirect effects on bone metabolism causing a decrease in both mineral and matrix content (Miyahara et al., 1980). These effects are probably accompanied by disturbances in collagen metabolism (Kucharz, 1988).

Previously, we noted that exposure of rats to $\mathrm{Cd}$ in drinking water leads to bone demineralization and a decrease in their mechanical properties (Brzóska et al., 2004). The current study was undertaken to determine the effect of 5 and $50 \mathrm{mg} \mathrm{Cd} / 1$ on collagen content and its solubility in bone of female rats.

\section{MATERIALS AND METHODS}

Animals. The study was performed on 3 week-old female Wistar rats of initial body mass of about $50 \mathrm{~g}$. All procedures were approved by the Local Ethics Committee for Animal Experiments in Białystok. The animals were housed in conventional conditions, at 22 $\pm 2^{\circ} \mathrm{C}$, with a relative humidity of $50 \pm 10 \%$ and a 12-h light/dark cycle. They had unlimited access to drinking water (redistilled water or water solutions of $\mathrm{CdCl}_{2}$ ) and rat chow (LSM dry diet, Agropol, Motycz, Poland) containing $1.11 \%$ calcium, $0.72 \%$ phosphorus, and $1 \mathrm{IU}$ vitamin $\mathrm{D}_{3} / \mathrm{g}$. Cadmium concentration in the diet was assessed in our laboratory to be $0.115 \mu \mathrm{g} / \mathrm{g}$. The rats were allocated randomly to three experimental groups, each consisting of four animals. Two groups received an aqueous solution of $\mathrm{CdCl}_{2}$ at the concentration of 5 or $50 \mathrm{mg} \mathrm{Cd} / 1$ as the only drinking fluid for 6 months. Control rats drank redistilled water (uncontaminated with Cd). At the end of the experiment, after overnight starvation, all animals were sacrificed under anaesthesia with Vetbutal (pentobarbital sodium and pentobarbital $5: 1,30 \mathrm{mg} / \mathrm{kg}$ b.m., i.p.). Femoral bones were removed for collagen analysis. The bone was cleansed of muscle tissue and weighed immediately after dissection.

Extraction and fractionation of type I and $\boldsymbol{V}$ collagens. Femurs free of adhering soft tissues were washed with $0.9 \% \mathrm{NaCl}$ to remove bone marrow and defatted with chloroform/methanol (2:1, v/v) for $24 \mathrm{~h}$. All steps of extraction and fractionation of collagen were performed at $4^{\circ} \mathrm{C}$. The bone was milled to a fine powder in $0.05 \mathrm{M}$ Tris/ $\mathrm{HCl}$ buffer, $\mathrm{pH}$ 7.5, containing the proteinase inhibitors: 10 $\mathrm{mM} N$-ethylmaleimide, $1 \mathrm{mM}$ phenylmethanesulphonyl fluoride and $1 \mathrm{mM}$ benzamidine. The suspension was decalcified by dialysis against $3 \times 1 \mathrm{l}$ of $50 \mathrm{mM}$ Tris/ $\mathrm{HCl}$ buffer, $\mathrm{pH}$ 7.5, containing 0.5 M EDTA for $24 \mathrm{~h}$ each. The decalcified bone matrix was dialyzed for $24 \mathrm{~h}$ against $2 \times 1 \mathrm{l}$ of deionized water and freeze-dried. The samples were weighed and extracted with $0.5 \mathrm{M}$ acetic acid $2 \times 24 \mathrm{~h}$. The acetic acid soluble collagen was separated by centrifugation at $15000 \times \boldsymbol{g}$ for $45 \mathrm{~min}$. The residue was subjected to limited digestion with pepsin (1 $\mathrm{mg}$ of pepsin/10 $\mathrm{mg}$ of demineralized bone) in $0.5 \mathrm{M}$ acetic acid (pH 2.0) for a further $2 \times 24 \mathrm{~h}$. The pepsin-solubilized collagens were separated by centrifugation at $15000 \times \boldsymbol{g}$ for $45 \mathrm{~min}$. The pepsin-insoluble bone matrix was extracted with $0.05 \mathrm{M}$ Tris/ $\mathrm{HCl}, \mathrm{pH} 7.5$, containing $4.0 \mathrm{M}$ guanidine hydrochloride for $24 \mathrm{~h}$. All three fractions were fractionated by differential salt precipitation. Type I molecules were precipitated with $\mathrm{NaCl}$ added to a final concentration of $2.6 \mathrm{M}, \mathrm{pH} 7.4$, by stirring for $24 \mathrm{~h}$ and collected by centrifugation at $15000 \times \boldsymbol{g}$ for 45 min. The supernatant was used for precipitation of type $\mathrm{V}$ collagen by further stirring with $\mathrm{NaCl}$ added to a final concentration of 4.5 M, pH 7.4, for $24 \mathrm{~h}$. The collagen precipitates collected by centrifugation were dissolved in $0.5 \mathrm{M}$ acetic acid and then dialyzed against $0.05 \mathrm{M}$ acetic acid to remove salt. Collagen concentration was assayed in each fraction according to the method of KomsaPenkova et al. (1996). For calibration curves 
purified type I collagen from calf skin and type V from human placenta (Sigma) were used.

The sum of acid-soluble and acid-insoluble collagen was defined as total collagen. Collagen solubility was expressed as the percentage of acid-soluble to total collagen.

SDS/urea/polyacrylamide gel electrophoresis. Electrophoretic analysis of collagen was performed according to Laemmli (1970) on $5 \%(\mathrm{w} / \mathrm{v})$ separating gel with a $3.5 \%$ (w/v) stacking gel, both gel solutions contained $2 \mathrm{M}$ urea. Collagen was detected by staining with silver (Schleicher \& Watterson, 1983).

Statistical analysis. The results were submitted to statistical analysis using one-way analysis of variance (ANOVA) followed by the Kruskal-Wallis ranks test, accepting $P<0.05$ as significant difference.

\section{RESULTS AND DISCUSSION}

Collagen extracted with acetic acid, pepsin and guanidine $\cdot \mathrm{HCl}$ from bone of control and Cd-exposed rats was analyzed electrophoretically on 5\% SDS/urea/polyacrylamide gel under non-reducing conditions (Fig. 1). All the fractions contained two types, I and V, of collagen as well as higher-order collagen (dimers and trimers) resulting from the 5-hydroxy-L-lysine-lysine covalent crosslinks. Employing differential salt fractionation described in details in Methods type I collagen was separated from type $\mathrm{V}$ collagen. Type V collagen accounted for about $3 \%$ of total collagen extracted from bone of both control and rats treated with $\mathrm{Cd}$. Exposure of rats to 5 or $50 \mathrm{mg} \mathrm{Cd} / \mathrm{l}$ increased the amount of both types of non-cross linked collagen in the fraction extracted with acetic acid as compared to controls (Fig. 2A). The main fraction over $90 \%$ of total collagen was acid-insoluble collagen obtained by pepsin digestion (Fig. 2B). The level of acid-insoluble collagen was lower in the bone of rats intoxicated with $\mathrm{Cd}$ than in controls (Fig. 2B, C). The treatment of rats with $5 \mathrm{mg} \mathrm{Cd} / 1$ did not affect the level of total collagen, whereas exposure to $50 \mathrm{mg}$ $\mathrm{Cd} / \mathrm{l}$ decreased it by about $14 \%$ (Fig. 3). Kawamura et al. (1978) reported that Cd affects the growth rate of rats leading to decrease in the bone collagen content. However, in our experimental conditions the intoxication of rats with either 5 or $50 \mathrm{mg} \mathrm{Cd} / 1$ had no effect on the growth rate (Brzóska et al., 2004). However, in the rats intoxicated with

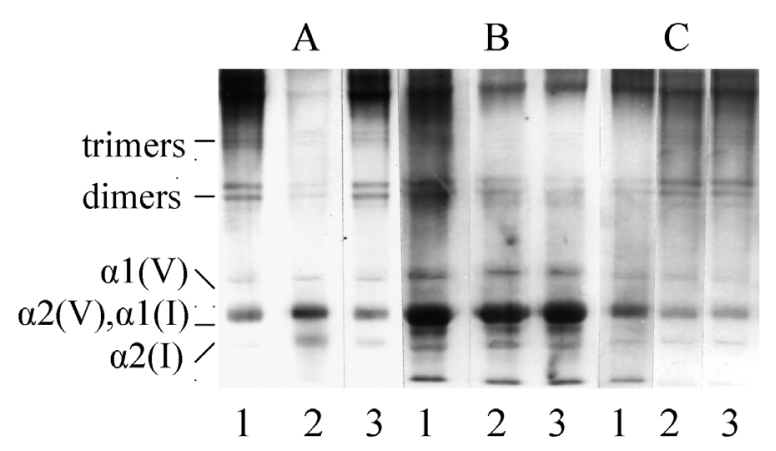

Figure 1. SDS/PAGE of collagen extracted from the femoral bone of rats.

Collagen was extracted with acetic acid (A), pepsin (B), and guanidine $\cdot \mathrm{HCl}(\mathrm{C})$ from the bone of control rats (lane 1) and rats intoxicated with 5 (lane 2) and $50 \mathrm{mg}$ $\mathrm{Cd} / 1$ (lane 3). Electrophoretic migration of $\alpha 1(\mathrm{I})$ and $\alpha 2(\mathrm{I})$ chains of type I collagen, cross-linked dimers and trimers of type I collagen as well as $\alpha 1(\mathrm{~V})$ and $\alpha 2(\mathrm{~V})$ chains of type $\mathrm{V}$ collagen are indicated.

$50 \mathrm{mg} \mathrm{Cd} / 1$ the mass of the femoral bone was decreased by about $8 \%$, which could result from demineralization of the bone by $\mathrm{Cd}$ (Brzóska et al., 2004). Furthermore, the decreased content of collagen probably caused by the Cd-induced inhibition of its biosynthesis or increased degradation could directly affect bone formation.

The solubility of collagen (determined as the percentage of the acetic acidsoluble fraction of total collagen) did not markedly depend on the $\mathrm{Cd}$ concentration used to intoxicate the rats. As can be seen from Fig. 4 in the bone of rats intoxicated with either 5 or $50 \mathrm{mg} \mathrm{Cd} / 1$ the solubility of type I collagen increased 2.9- 


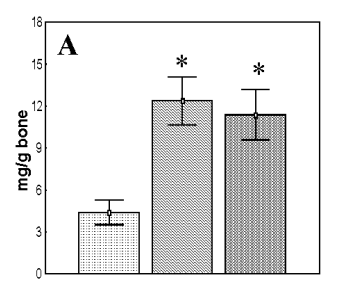

\section{COLLAGEN I}
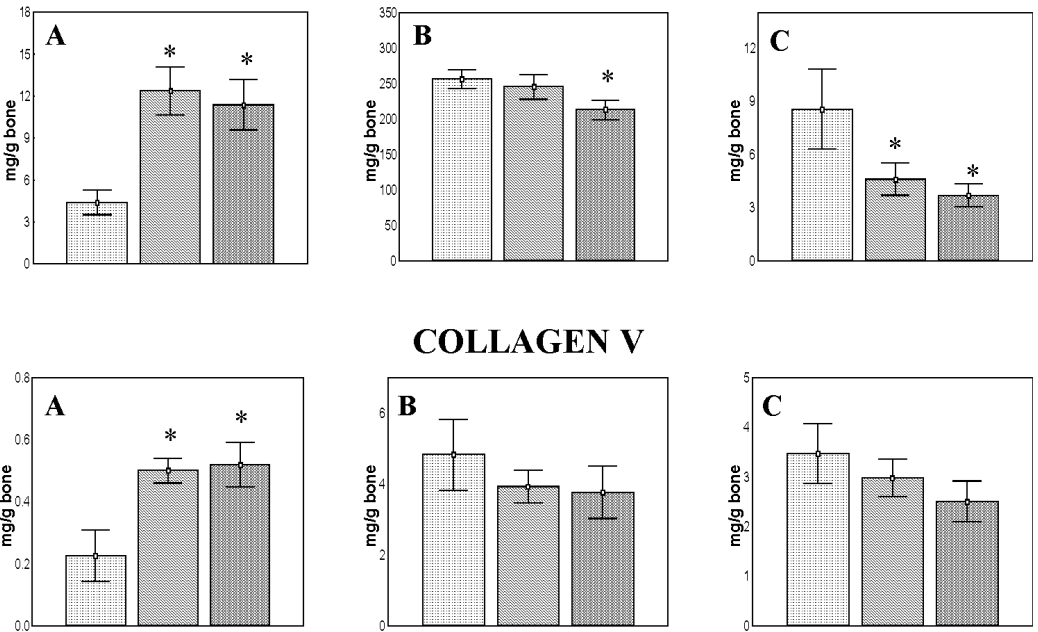

Control

$5 \mathrm{mg} \mathrm{Cd} / \mathrm{l}$

$50 \mathrm{mg} \mathrm{Cd} / \mathrm{l}$

Figure 2. Effect of cadmium on the amount of collagen extracted with acetic acid (A), pepsin (B), and guanidine $\cdot \mathrm{HCl}(\mathrm{C})$.

Experimental data are mean \pm S.D. of triplicate determinations. ${ }^{*} P<0.05$ compared to the control.

and 3-fold, respectively. Similarly, for type V collagen the solubility increased 2.3- and 2.7-fold, respectively.

Our results indicate that $\mathrm{Cd}$ influences the solubility and content of collagen type I and V in the bone of intoxicated rats, but the mechanism of these changes remains unclear.

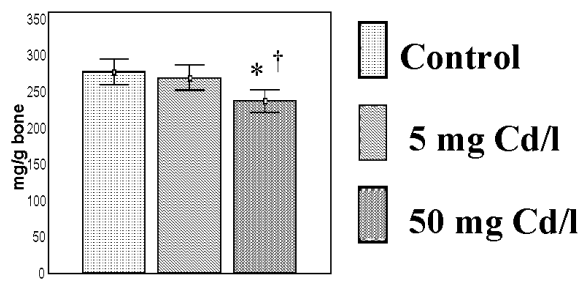

Figure 3. Effect of cadmium on the level of total extracted collagen.

Experimental data are mean \pm S.D. of triplicate determinations. ${ }^{*} P<0.05$ compared to the control, ${ }^{\dagger} P<0.05$ compared to $5 \mathrm{mg} \mathrm{Cd} / \mathrm{l}$.

Iguchi \& Sano (1982) have reported that Cd has an inhibitory effect on bone lysyl oxidase responsible for forming the cross-linking of fibrils. The strength of collagen fibrils is derived mainly from the intermolecular cross-links; reduction in their frequency leads to increased collagen solubility and loss of strength (Oxlund et al., 1995). The increase in collagen solubility could be caused by formation of underhydroxylated collagen resulting in decreased thermal stability and in consequence increase its degradation. Underhydroxylated collagen is characterized by electrophoretic migration different than normal. Analysis of collagen from the femur bones of control and Cd-treated rats on

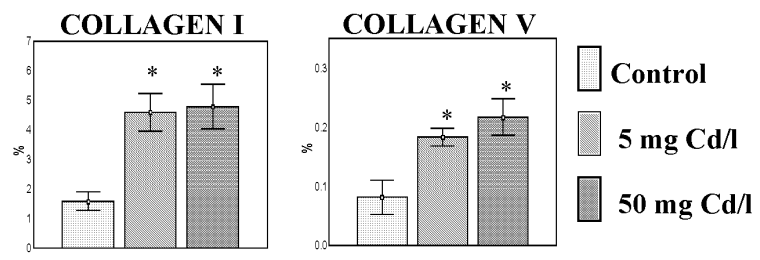

Figure 4. Effect of cadmium on the solubility of collagen.

Experimental data are mean \pm S.D. of triplicate determinations. $* P<0.05$ compared to the control.

SDS/urea/polyacrylamide gel indicated comparable migration of collagen chains suggesting the same level of hydroxylation (Fig. 1). It was also reported that $\mathrm{Cd}$ strongly inhibits 
procollagen C-endopeptidase which may cause suppression of collagen fibril formation (Hojima et al., 1994).

Proper amount and structure of collagen fibers play an important role for bone formation and strength. Type V collagen forms heterotypic fibrils with type I and it may have some regulatory role on fibril diameter and orientation, as has been shown for cornea (Birk et al., 1988). Thus, any disturbances in collagen metabolism may result in the formation of low quality bone tissue susceptible to deformation and fractures.

\section{R E F E R E N C E S}

Birk DE, Fitch JM, Babiarz JP, Linsenmayer TF. (1988) Collagen type I and V are present in the same fibril in avian corneal stroma. $J$ Cell Biol.; 106: 999-1008.

Brzóska MM, Moniuszko-Jakoniuk J, Jurczuk M, Gałażyn-Sidorczuk M, Rogalska J. (2001) The effect of zinc supply on cadmium-induced changes in the tibia of rats. Food Chem Toxicol.; 39: 729-34.

Brzóska MM, Majewska K, Moniuszko-Jakoniuk J. (2004) Mineral status and mechanical properties of lumbar spine of female rats chronically exposed to various levels of cadmium. Bone.; 34: 517-26.

Hojima Y, Behta B, Romanic AM, Prockop DJ. (1994) Cadmium ions inhibit procollagen C-proteinase and cupric ions inhibit procollagen N-proteinase. Matrix Biol.; 14: 113-20.

Iguchi H, Sano S. (1982) Effect of cadmium on the bone collagen metabolism of rat. Toxicol Appl Pharmacol.; 62: 126-36.

Järup L. (2002) Cadmium overload and toxicity. Nephrol Dial Transplant.; 17 (Suppl 2): 35-9.
Katsuta O, Hiratsuka H, Matsumoto J, Iwata H, Toyota N, Tsuchitani M, Umemura T, Marumo F. (1994) Cadmium-induced osteomalacic and osteopetrotic lesions in ovariectomized rats. Toxicol Appl Pharmacol.; 126: 58-68.

Kawamura J, Yoshida O, Nishino K, Itokawa Y. (1978) Disturbances in kidney functions and calcium and phosphate metabolism in cadmium poisoned rats. Nephron.; 20: 101-10.

Kjellström T. (1992) Mechanism and epidemiology of bone effects of cadmium. IARC Sci Publ.; 118: 301-10.

Komsa-Penkova R, Spirova R, Bechev B. (1996) Modification of Lowry's method for collagen concentration measurement. $J$ Biochem Biophys Methods.; 32: 33-43.

Kucharz EJ. (1988) Effect of cadmium intoxication on collagen and elastin content in tissues of the rat. Bull Environ Contam Toxicol.; 40: 273-9.

Laemmli UK. (1970) Cleavage of structural proteins during the assembly of the head of bacteriophage T4. Nature (Lond.).; 227: $680-5$.

Miyahara T, Miyakoshi M, Kozuka H. (1980) Inhibitory effect of cadmium on the mineralization of embryonic chick femurs in tissue culture. Jpn J Public Health.; 27: 323-8.

Oxlund H, Barckman M, Ortoff G, Andreassen TT. (1995) Reduced concentrations of collagen cross-links are associated with reduced strength of bone. Bone.; 17: 365S-71S.

Schleicher M, Watterson DM. (1983) Analysis of differences between Coomassie blue stain and silver stain procedures in polyacrylamide gels: conditions for the detection of calmodulin and troponin C. Anal Biochem.; 131: 312-7. 